\title{
A Case of Endoscopic Resection of a Colonic Semipedunculated Leiomyoma
}

\author{
Seung Hwa Lee, Gun Yoong Huh ${ }^{1}$, Yoo Seock Cheong \\ Health Promotion Center, Dankook University College of Medicine, Cheonan; ${ }^{1}$ Department of Surgery, Osan Hankook Hospital, Osan, Korea
}

\begin{abstract}
During colonoscopic examination, epithelial lesions, such as adenomatous polyps, are frequently encountered, unlike subepithelial lesions, such as leiomyomas, which are uncommon. A colonic leiomyoma is a rare tumor, originating either from the mucularis mucosa or from the proper muscle, and accounts for only $3 \%$ of all gastrointestinal leiomyomas. Colonic leiomyomas are usually benign and asymptomatic. However, they can sometimes cause symptoms, ie, abdominal pain, intestinal obstruction, hemorrhage, and perforation. The traditional management option for a colonic leiomyoma is surgical resection. Recently, with the development of endoscopy devices and techniques, the endoscopic resection has been considered as an alternative treatment option. We experienced a patient with a leiomyoma that was diagnosed during colonoscopy. The leiomyoma was resected endoscopically without complication. We report this case with a review of the literature.
\end{abstract}

Keywords: Leiomyoma; Colonoscopy; Endoscopic resection; Subepithelial lesion

\section{INTRODUCTION}

Since its first introduction in 1969, colonoscopy has been accepted as the best tool for the diagnosis and follow up of colorectal diseases [1]. Therefore, the demand for colonoscopy is rapidly growing worldwide. During colonoscopy, epithelial lesions, such as adenomatous polyps, are frequently encountered, unlike subepithelial lesions, such as leiomyomas, which are uncommon.

Colonic leiomyomas are smooth muscle cell tumors originating from either the muscularis mucosa or the proper muscle. These tumors may occur throughout the entire digestive tract, but are rarely seen in the colon and the rectum, where they account for only $3 \%$ of all gastrointestinal (GI) leiomyomas [2]. Most of the patients with colonic leiomyomas are usually asymptomatic. However, they can sometimes have symptoms such as abdominal pain, intestinal obstruction, hemorrhage and perforation, especially when

Received: April 30, 2011 Accepted: May 17, 2011

Correspondence to: Yoo Seock Cheong, M.D.

Health Promotion Center, Dankook University College of Medicine,

San16-5 Anseo-dong, Dongnam-gu, Cheonan 330-715, Korea

Tel: +82-41-550-6385, Fax: +82-41-550-3998

E-mail:drloved@hanmail.net

(C) 2011 The Korean Society of Coloproctology

This is an open-access article distributed under the terms of the Creative Commons Attribution NonCommercial License (http://creativecommons.org/licenses/by-nc/3.0) which permits unrestricted noncommercial use, distribution, and reproduction in any medium, provided the original work is properly cited. the tumors are large. Because an endoscopic resection still has a high risk of perforation, subepithelial lesions, such as colonic leiomyomas, are usually treated by a surgical resection [3]. However, with the recent improvement of endoscopic devices and techniques, an endoscopic resection has been increasingly considered as an alternative option [4].

We experienced a patient with a leiomyoma of the sigmoid colon diagnosed during colonoscopy. The leiomyoma was successfully resected endoscopically without complication. We report this case with a review of the literature.

\section{CASE REPORT}

A 54-year-old man who had suffered from mild, intermittent, and diffuse lower abdominal pain for two months visited our hospital for examination. No other abdominal symptoms (e.g., nausea, vomiting, diarrhea, constipation or hematochezia) were present. In his past history, he had hypertension, which was well-controlled by medication. The patient had no other medical illness or surgical history. He had been a smoker, 10 to 12 cigarettes per day, since the age of 30. However, he never drank alcohol.

Physical examination was unremarkable. Laboratory tests, including complete blood cell counts, aspartate aminotransferase, alanine aminotransferase, protein, albumin, electrolyte, blood urea nitrogen, creatinine, glucose, urine analysis and stool examination, were within normal limits. Radiologic evaluation, including chest X-ray, 

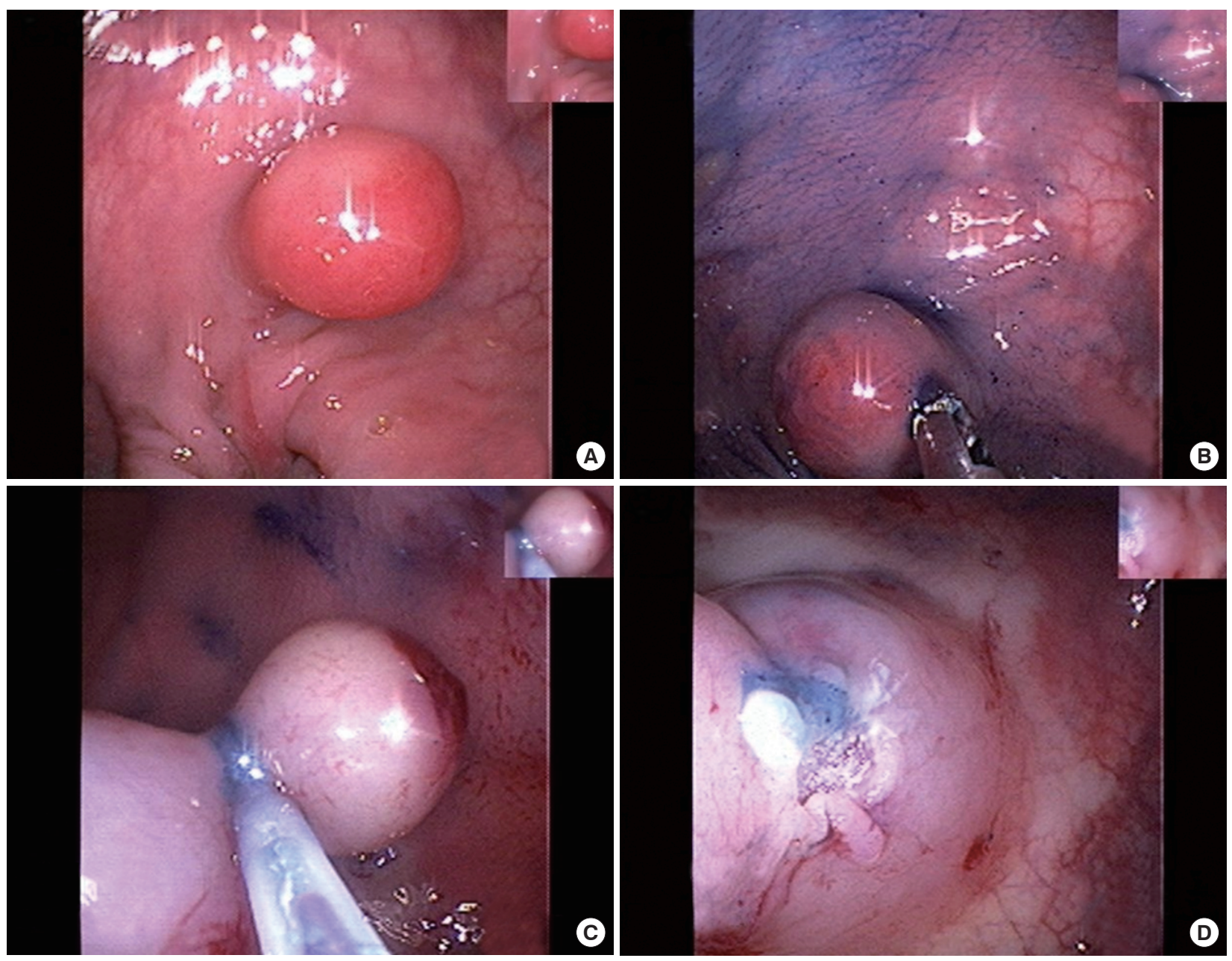

Fig. 1. Endoscopic resection of a semi-pedunculated polyp of the sigmoid colon. (A) A semipedunculated polyp with a smooth surface was observed in the sigmoid colon. (B) The cushion sign by using a forcep was negative. (C) After submucosal injection of an epinephrine/saline mixed solution, a snare polypectomy with electrocauterization was performed. (D) No complications (e.g., bleeding or perforation) were noted at the resection site.

abdomen supine/erect X-ray and abdominal sonography, showed nothing abnormal.

An esophagogastrodudenoscopy showed unremarkable finding, except for chronic superficial gastritis. After colon preparation with $4 \mathrm{~L}$ of a polyethylene glycol electrolyte solution, colonscopy was performed the next day. During colonoscopy, about a 15 -mm-sized semi-pedunculated polyp-like lesion was observed in the sigmoid colon (Fig. 1A). It had a smooth surface and was hard (cushion sign, negative) (Fig. 1B). After an epinephrine/saline mixed solution $(1: 10,000)$ had been injected into the base of the lesion, it was lifted (lifting sign, positive), and a snare polypectomy was done (Fig. 1C). The lesion was removed successfully without any complications (Fig. 1D).

For differential diagnosis, immunohistopathologic examination was done. The lesion was nodular and consisted of interlacing bundles of smooth muscle cells. The lesion cells were spindle-shaped and had bland-looking nuclei without atypia (Fig. 2). They were originating from the muscularis mucosa. There was no evidence of coagulation, necrosis or hemorrhage. In the immunohistochemistry analysis, cells were diffusely positive for smooth muscle actin (Fig. 3) while definitely negative for c-kit (CD117) (Fig. 4). With these findings, a gastrointestinal stromal tumor was excluded, and a colonic leiomyoma was diagnosed.

After the lesion removal, the patient's symptom was improved. Follow-up colonoscopy revealed no recurrence after six months.

\section{DISCUSSION}

The leiomyoma, a benign smooth muscle tumor, was first described by Virchow in 1854 [5]. It often arises in the uterus of a woman, but may also arise in the skin, nipple, scrotum, and labia; however, it develops less frequently in the GI tract. A GI leiomyoma may 

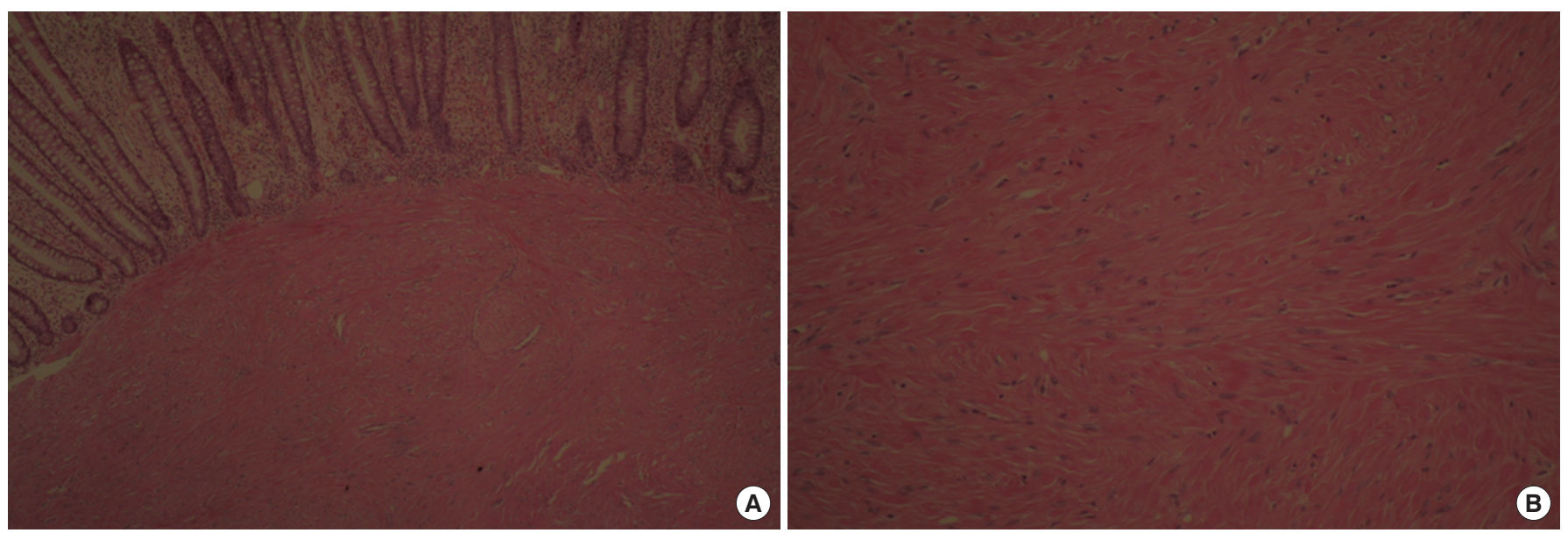

Fig. 2. Slides showing proliferation of spindle-shaped smooth muscle cells. The cells originated in the muscularis propria and had bland-looking nuclei without atypia $(\mathrm{A}: \mathrm{H} \& \mathrm{E}, \times 40 ; \mathrm{B}: \mathrm{H} \& \mathrm{E}, \times 100)$.
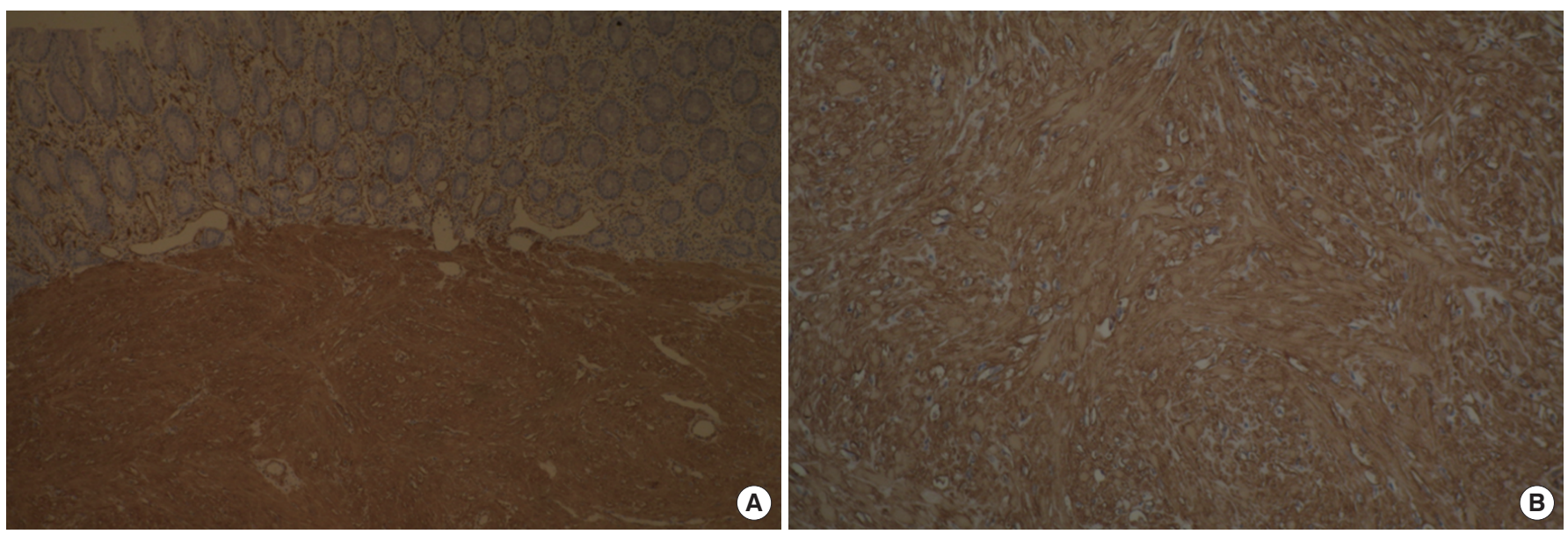

Fig. 3. Slides showing that cells were diffusely positive for smooth muscle actin staining $(A, \times 40 ; B, \times 100)$.
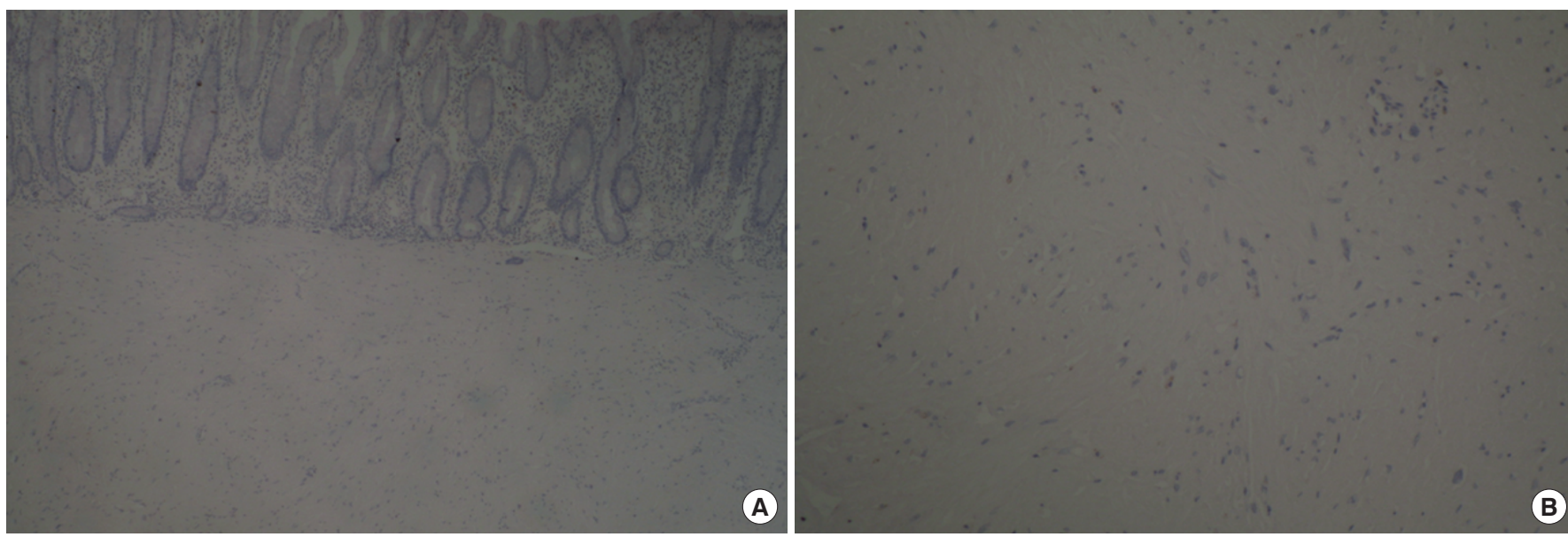

Fig. 4. Slides showing that cells were negative for c-kit (CD117) staining $(A, \times 40 ; B, \times 100)$. 
occur anywhere in the digestive tract. However, most are found in the esophagus or stomach, and they have been noted in the colon only occasionally. In a survey of smooth muscle tumors of the digestive tract, Baker and Good [2] reported that $65 \%$ of leiomyomas were found in the esophagus or stomach, $23 \%$ in the small intestine and only $3 \%$ in the colon. Most colonic leiomyomas occur in the sigmoid colon or the transverse colon and are usually solitary; however, they may also be multiple. Furthermore, the majority of cases occur in adults between the ages 30 and 50 years. Colonic leiomyomas are rare, and to the best of our knowledge, only 5 cases have been previously reported in Korea (Table 1).

A GI leiomyoma is a benign subepithelial tumor that is usually covered with normal epithelium and has the characteristics of a mesenchymal tumor of the digestive tract. Mesechymal tumors of

Table 1. Summary of case reports on colonic leiomyomas in Korea

\begin{tabular}{|c|c|c|c|c|c|}
\hline Case & Sex/age & Size, shape & Location & Symptom & Method of removal \\
\hline Lee et al. [11] 2000 & Male/18 & $\begin{array}{c}40 \mathrm{~mm} \\
\text { semi-pedunculated }\end{array}$ & Descending colon & $\begin{array}{l}\text { Mass, hematochezia, } \\
\text { abdominal pain }\end{array}$ & Open surgery \\
\hline Lee et al. [12] 2002 & Female/51 & $\begin{array}{c}20 \mathrm{~mm} \text {, } \\
\text { pedunculated }\end{array}$ & Hepatic flexure & $\begin{array}{l}\text { Abdominal pain, } \\
\text { weight loss }\end{array}$ & EMR \\
\hline Cho et al. [13] 2004 & Female/65 & $\begin{array}{l}10 \mathrm{~mm} \text {, } \\
\text { pedunculated }\end{array}$ & Splenic flexure & Hematochezia & EMR \\
\hline Park et al. [4] 2008 & Male/54 & $\begin{array}{c}10 \mathrm{~mm}, \\
\text { pedunculated }\end{array}$ & Sigmoid colon & Loose stool & EMR \\
\hline Cho et al. [14] 2009 & Female/59 & $\begin{array}{c}10 \mathrm{~mm} \\
\text { semi-pedunculated }\end{array}$ & Rectum & $\begin{array}{l}\text { Screening } \\
\text { (Asymptomatic) }\end{array}$ & EMR \\
\hline
\end{tabular}

EMR, endoscopic mucosal resection.
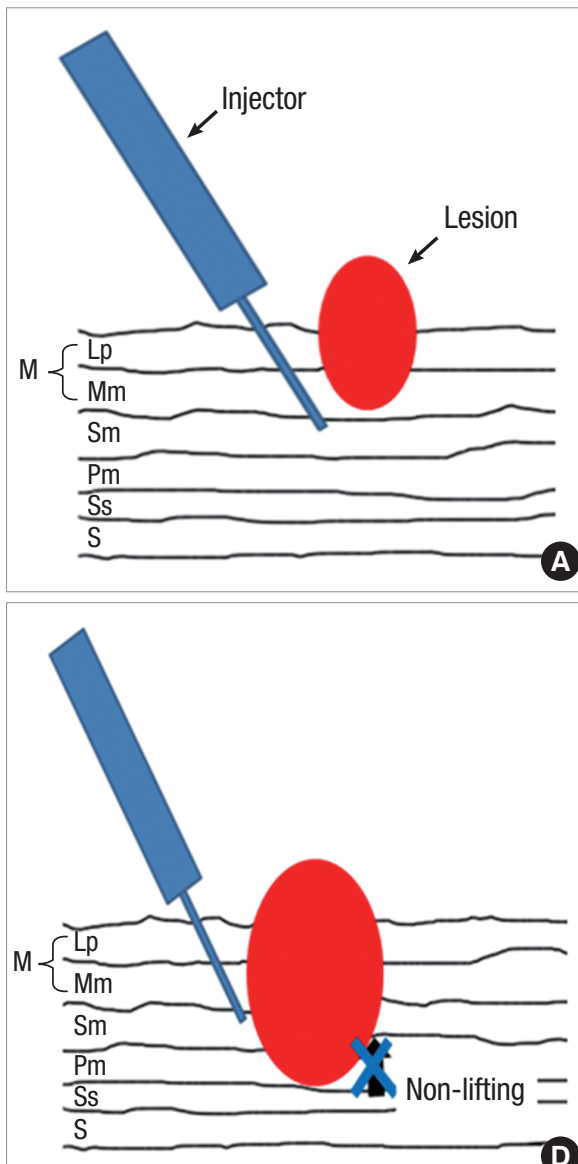
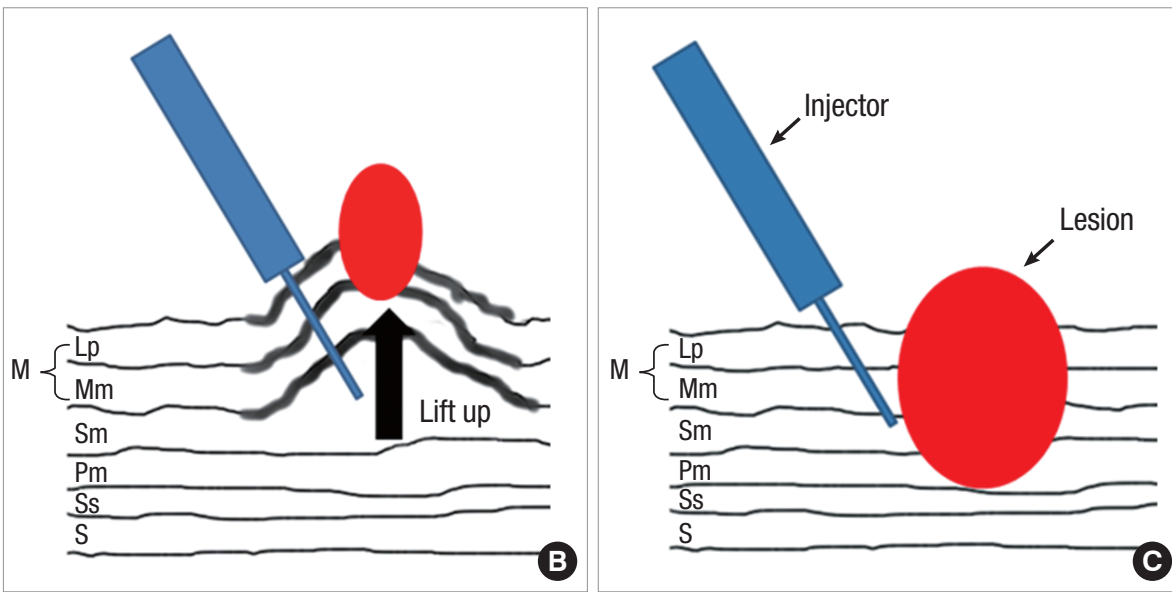

Fig. 5. Schematic of the submucosal injection and lifting sign. (A) and (B) are positive lifting sign-indication of an endoscopic resection. (C) and (D) are negative lifting sign-contraindication of an endoscopic resection. $\mathrm{M}$, mucosa; Lp, lamina propria; Mm, muscularis mucosa; Sm, submucosa; Pm, proper muscle; Ss, subserosa; S, serosa. 
the digestive tract are classfied by the WHO into gastrointestinal stromal tumors (GIST), lipomas, leiomyomas, leiomyosarcomas, angiosarcomas, and Kaposi sarcomas [6]. Overall, mesenchymal tumors are thought to represent only $1 \%$ of primay GI cancers. Due to their similarity in appearance under light microscopy, it is important to distinguish a leiomyoma from a GIST. They can be differentiated by using immunohistochemistry and electron microscopy. A GIST is believed to originate from Cajar cells and is usually stained with c-kit (CD117) [7] while a leiomyoma is believed to originate from smooth muscle cells and is usually stained for smooth muscle actin or desmin, but not for c-kit. Similarity, in our case, the resected tumor was positive for smooth muscle actin and negative for c-kit.

Colonic leiomyomas are usually asymptomatic. Hence, they are found incidentally during colonoscopy. However, they can sometimes cause symptoms, such as abdominal pain, intestinal obstruction, hemorrhage and perforation [8]. The clinical manifestation depends on the location, size and direction of the tumor growth. In our case, the patient with a colonic leiomyoma had mild, diffuse, lower abdominal pain. The hypotheses for the origin of pain associated with these lesions are as follows [9]: 1) local pressure exerted by the tumor on nerves; 2) the role of specific infiltrating cells-one study of 24 angio-leiomyomas revealed that painful tumors had fewer mast cells than asymptomatic tumors; and 3) the contraction of muscle cells, which may be pivotal in the induction of pain. However, the mechanism of pain is still controversial.

Although the traditional management option for a colonic leiomyoma is surgical resection, this concept has been challenged recently. Following the development of new devices and techniques, endoscopic resection has been considered to be an alternative treatment option [10]. A leiomyoma can grow from either the muscularis mucosa or the proper muscle layer. If the colonic leiomyoma arises from the muscularis mucosa above the submucosal layer, it can be successfully removed by using an endoscopic resection; however, despite that fact, in general, endoscopic resection is considered to increase the risk of perforation. The procedure can be confirmed by using a submucosal injection technique. If a lesion cannot be lifted by using a submucosal injection of saline (lifting sign, negative), it is likely to be a lesion with deep submucosal invasion or to originate from the proper muscle layer, which is a contraindication for endoscopic removal (Fig. 5). In our case, we injected an epinephrine/saline mixed solution $(1: 10,000)$ into the base of the lesion, and it was lifted. After lifting of the lesion had been confirmed, it was removed endoscopically without any complications (e.g., bleeding or perforation). In conclusion, we believe that an endoscopic resection of a colonic sub-penduculated leiomyoma can be successful, reducing medical costs and avoiding unnecessary surgery, which in the present case, for example, could have led to scars and psychological distress.

\section{CONFLICT OF INTEREST}

No potential conflict of interest relevant to this article was reported.

\section{REFERENCES}

1. Wolff WI, Shinya H. Colonofiberoscopy. JAMA 1971;217:1509-12.

2. Baker HL Jr, Good CA. Smoothmuscle tumors of the alimentary tract; their roentgen manifestations. Am J Roentgenol Radium Ther Nucl Med 1955;74:246-55.

3. Jovanovic I, Cvejic T, Popovic D, Micev M. Endoscopic removal of pedunculated leiomyoma of the sigmoid colon (case report and literature review of dignostic and treatment options). Acta Chir Iugosl 2006;53:87-9.

4. Park YW, Cho YS, Kim JS, Son HS, Kim HK, Kim SS, et al. Endoscopic resection of a pedunculated colonic leiomyoma resembling a hyperplastic polyp. Korean J Gastrointest Endosc 2008;37:218-21.

5. Xu GQ, Zhang BL, Li YM, Chen LH, Ji F, Chen WX, et al. Diagnostic value of endoscopic ultrasonography for gastrointestinal leiomyoma. World J Gastroenterol 2003;9:2088-91.

6. Miettinen M, Furlong M, Sarlomo-Rikala M, Burke A, Sobin LH, Lasota J. Gastrointestinal stromal tumors, intramural leiomyomas, and leiomyosarcomas in the rectum and anus: a clinicopathologic, immunohistochemical, and molecular genetic study of 144 cases. Am J Surg Pathol 2001;25:1121-33.

7. Miettinen M, Sarlomo-Rikala M, Sobin LH. Mesenchymal tumors of muscularis mucosae of colon and rectum are benign leiomyomas that should be separated from gastrointestinal stromal tumors-a clinicopathologic and immunohistochemical study of eightyeight cases. Mod Pathol 2001;14:950-6.

8. Chow WH, Kwan WK, Ng WF. Endoscopic removal of leiomyoma of the colon. Hong Kong Med J 1997;3:325-7.

9. Cummings SP, Lally KP, Pineiro-Carrero V, Beck DE. Colonic leiomyoma: an unusual cause of gastrointestinal hemorrhage in childhood. Report of a case. Dis Colon Rectum 1990;33:511-4.

10. Oka S, Tanaka S, Kanao H, Ishikawa H, Watanabe T, Igarashi M, et al. Current status in the occurrence of postoperative bleeding, perforation and residual/local recurrence during colonoscopic treatment in Japan. Dig Endosc 2010;22:376-80.

11. Lee HH, Lee KS, Jeon WJ, Seo JC, Yang YM, Jeong JB, et al. A case of adult intussusception of the colon caused by leiomyoma. Korean J Gastrointest Endosc 2000;21:654-7.

12. Lee HL, Baik GH, Kim JH, Baek IH, Hahn TH, Park HJ, et al. Pedunculated colonic leiomyoma-diagnosed and removed by endoscopic resection. Korean J Gastrointest Endosc 2002;25:217-9.

13. Cho HS, Kim HY, Song YL, Yoon HS, Kim HS, Koh CO, et al. A case of pedunculated leiomyoma found during colonoscopic examination for anal Bleeding. Korean J Gastroenterol 2004;43:129-32.

14. Cho SW, Kim HY, Yang US. Rectal leiomyoma diagnosed by endoscopic ultrasonography and endoscopic polypectomy. Korean J Gastrointest Endosc 2009;38:151-5. 